\title{
UM ESTUDO SOBRE CRECHES COMO AMBIENTE DE DESENVOLVIMENTO
}

\author{
ANA BEATRIZ ROCHA LIMA \\ Programa de Pós-Graduação em Educação da Universidade do Vale do Itajaí - SC \\ beatriz@univali.br
}

\section{ELIANA BHERING}

Programa de Pós-Graduação em Educação da Universidade Federal do Rio de Janeiro eliana.bhering@terra.com.br

\begin{abstract}
RESUMO
Preparar o ambiente de sala para crianças entre quatro e 36 meses tem sido um desafio para a educação infantil - El. A despeito do fato de crianças pequenas serem tradicionalmente educadas no seio da família, o número de pais que procuram escolas de educação infantil vem crescendo rapidamente. Por isso, estudar as possibilidades da sala e da instituição para estas crianças constitui, hoje, um importante tema de investigação. Diversas áreas de conhecimento discutem o impacto do ambiente no comportamento e no desenvo/vimento das crianças pequenas, como também nas interações e ações dos envolvidos no processo educativo. Avaliar a qualidade do ambiente para essas crianças é, portanto, primordial. Na pesquisa, avaliamos todas as creches de um município de Santa Catarina - um total de doze salas - utilizando a escala Iters- $R$, traduzida e testada para o português. Os itens Atividades e Cuidado Pessoal tiveram os escores médios mais baixos em todas as instituições; Interação e Pais e equipe, os escores médios mais altos. Quanto às turmas, as de três anos foram as que apresentaram os piores resultados. A utilização desse instrumento desencadeia discussões produtivas sobre a qualidade do ambiente para crianças pequenas.

CRECHES - AVALIAÇÃO - DESENVOLVIMENTO DA CRIANÇA - EDUCAÇÃO INFANTIL
\end{abstract}

\section{ABSTRACT}

A STUDY ON DAY-CARE CENTERS AS DEVELOPMENT CONTEXT. Preparing the classroom environment for babies and toddlers has been a current challenge for day care

Este artigo é uma síntese da comunicação submetida à Reunião Anual da Associação Nacional de Pós-Graduação e Pesquisa em Educação - Anped, 2006. A pesquisa foi desenvolvida com apoio do programa de bolsas de mestrado da Universidade do Vale do Itajaí - Univali -, e faz parte de um projeto mais amplo envolvendo outras universidades brasileiras. 
center's professionals all over the world. Despite the fact that young children in Brazil have been traditionally looked after by family members, the number of parents looking for quality day care centers is growing rapidly. Therefore, having groups of babies and toddlers attending such centers from a very early age has proved to be a topic worth studying. Many disciplines have emphasized that context is an important aspect to consider, since it has a great impact on development. Assessing the quality of the environment prepared for young children in Brazil is, consequently, of utmost importance. This study intended to assess all day care centers in a small town in the southern of Brazil (a total of I 2 classrooms), employing Iters-R scale, which were translated into Portuguese and tested. Findings indicate that Activities and Personal Care items had the lower medium score of all institutions; Interaction and Parents and Team had the higher one. Of all the groups, the 3 years old had been the one that presented the worse results. The use of this instrument promotes productive discussions about the quality of environment for small children.

DAY NURSERIES - EVALUATION - CHILD DEVELOPMENT - EARLY CHILDHOOD EDUCATION

Os serviços destinados a crianças pequenas configuram-se a partir dos contextos sociais, políticos e econômicos, que delineiam alguns aspectos dos ambientes educativos infantis referentes à organização e aos recursos destinados aos serviços da creche (Demo, 1994; Guimarães, 2002).

A organização do ambiente oferecido às crianças pequenas depende das características dos contextos em que elas vivem e que freqüentam, e do que eles podem oferecer. Em instituições de Educação Infantil (EI), são importantes o ambiente físico, o grupo de atividades, a rotina, os recursos materiais e de pessoal, as interações desenvolvidas e o programa adotado pela instituição para essa faixa etária (Lordelo, 2002). A preocupação com a organização desse ambiente relaciona-se com o desenvolvimento infantil, considerado como um processo aberto, dinâmico, contínuo e multifacetado, e também com a socialização das crianças.

No Brasil, os ambientes físicos destinados à educação infantil infelizmente ainda são inadequados, e muitas vezes sua organização é precária, com situações de confinamento, entorno degradado, ordenação rígida da sala, utilização de lápis e papel visando a antecipação da escolaridade das crianças pequenas, ausência de brinquedos, rotinas inflexíveis e uso abusivo da televisão e do tempo de espera (Rosemberg, 2003).

A discussão acerca da organização dos ambientes destinados às crianças pequenas fornece subsídios para o estabelecimento de critérios e parâmetros 
para o desenvolvimento de programas educativos de qualidade, voltados às necessidades específicas de cada faixa etária (Saluja, Early e Clifford, 2002). A avaliação desses ambientes e dos programas educativos é essencial, pois auxilia o professor e a equipe pedagógica na reflexão sobre seu desempenho e sobre o impacto deste na ação das crianças. $\bigcirc$ monitoramento das condições ambientais tem em vista também as condições para o desenvolvimento infantil, como por exemplo, a ênfase dada ao desenvolvimento cognitivo ou das habilidades sociais, e busca identificar a falta de investimento em alguns dos componentes do programa (Gallager, Clifford, 2000; Aguiar, Bairrão, Barros, 2002).

A avaliação dos ambientes educativos para crianças pequenas é um desafio, e deve ser vista como um mecanismo de constante reflexão sobre os elementos que compõem este ambiente, e não simplesmente como um mecanismo para medir, julgar, comparar ou selecionar os contextos para as crianças (Bondioli, 2004). A avaliação, mesmo que desencadeada por instrumentos previamente estipulados, é um processo, e não deve ser tomada como um produto final, sem considerar a dinâmica das ações das instituições. Resultados estáticos representarão somente situações pontuais desenvolvidas em um dado momento, ao invés de retratar o trabalho da instituição. Na medida em que visa fomentar o crescimento e desenvolvimento de todos os envolvidos, adultos e crianças, e permeia a construção de situações educativas intencionais de qualidade. A avaliação que busca um diagnóstico da situação a partir da qual o programa é desenvolvido, mesmo que seus resultados se refiram a um momento determinado, pode favorecer o processo de mudança necessário para atingir os parâmetros de qualidade estipulados ou aspirados pela equipe.

Os termos ambiente e contexto empregados neste artigo representam os aspectos físicos e materiais, relacionais, sociais, e os recursos humanos da educação infantil. Com isso, toda a dinâmica da rotina, atividades, cuidados e interações, desenvolvida nos ambientes designados para as crianças nos Centros de Educação Infantil (CEI), será considerada na avaliação do ambiente/ contexto.

Nossa pesquisa teve como objetivo geral avaliar as condições do ambiente dos cinco centros de educação infantil (quatro públicos e um privado, de caráter filantrópico) da rede municipal de um município na região do Vale do Itajaí, em Santa Catarina. 


\section{REVISÃO BIBLIOGRÁFICA}

Pesquisas sobre a maneira como o ambiente físico é disposto e organizado, tanto internamente nas salas, quanto externamente nos pátios, indicam que existe uma relação entre o arranjo espacial e o tipo de interações estabelecidas entre as crianças, entre as crianças e a equipe, e entre as crianças e os materiais disponíveis para suas atividades. Segundo essas pesquisas, a quantidade e a qualidade das interações estão relacionadas com o tipo de arranjo espacial (Bomfim, 2002; Campos-de-Carvalho, Rubiano, 1996, 1996a; Campos-de-Carvalho, Padovani, 2000; Sager et al., 2003). A preocupação com o ambiente para crianças nesta faixa etária, no entanto, ultrapassa a questão física do ambiente estendendo a discussão para aspectos como, por exemplo, rotinas, atividades, formação dos profissionais e participação da comunidade e dos pais nos programas (Harms, Cryer, Clifford, 2003).

A preocupação com as características necessárias para o estabelecimento e desenvolvimento de programas de qualidade para a educação infantil é compartilhada por muitos pesquisadores dessa área (Aguiar, Bairrão, Barros, 2002; Becchi, Bondioli, 2003; Bhering, 2004; Bondioli, Mantovani, 1998, Zabalza, 1998). Em 1990, a Comunidade Européia iniciou um debate sobre a questão da qualidade, que culminou na publicação do documento "Qualidade para os serviços para a criança pequena" (Moss, 2002). Esse documento gerou outros, que estabelecem metas de qualidade para esses serviços, atribuindo grande importância ao cuidado infantil, no que diz respeito ao trabalho, igualdade de gênero, igualdade de oportunidades para crianças urbanas e rurais, igualdade de responsabilidades familiares de homens e mulheres e diversidade e flexibilidades dos serviços prestados às crianças (Moss, 2002; Haddad, 2002). Esses documentos vêm influenciando as ações para a infância na Europa, e inspiram algumas iniciativas no Brasil. A discussão sobre qualidade inclui a reflexão sobre a construção do ambiente para crianças entre quatro meses e seis anos de idade.

Pesquisadores do Centro Frank Porter Child Development, da Universidade da Carolina do Norte, nos Estados Unidos, buscam identificar os elementos necessários para produzir um sistema educacional com qualidade. Destacam, entre outros, a preparação da equipe, a consultoria externa, as pesquisas aplicadas e os programas de avaliação, a comunicação entre as pes- 
soas envolvidas no processo, um sistema de dados com informações atualizadas, um planejamento adequado e claro, e uma coordenação organizada desses componentes (Gallager, Clifford, 2000).

Katz ( 1993 ) indica cinco referências para medir a qualidade de um programa de educação infantil: a proporção de crianças para cada adulto, qualificações e estabilidade da equipe, características das interações entre crianças e adultos, qualidade e quantidade de equipamentos, qualidade e quantidade de materiais e dos ambientes destinados à educação infantil. A saúde, a higiene e as medidas de segurança são indicadores de um programa com qualidade. Aguiar, Bairrão e Barros (2002) afirmam que há um consenso em torno desses critérios para a determinação da qualidade nos cuidados e na educação das crianças.

Para Bondioli (2004), que estuda as condições das creches da região de Reggio Emilia, a qualidade tem uma natureza transacional, participativa, autoreflexiva, contextual e plural, transformadora, e é um processo. Não é um valor absoluto, pois cada contexto tem sua história e razões para desenvolver seu trabalho de uma maneira única. A qualidade, para a autora, "tem derivação flexível, admite modalidades de realização diferentes, ênfase de prioridades, idiossincrasias" (p. 16).

No cenário brasileiro, alguns princípios de qualidade foram propostos por Campos e Rosemberg ( 1995 ) para o trabalho em creches: respeitar os direitos fundamentais da criança, com critérios relativos à organização e ao funcionamento interno, possibilitar à criança o direito à brincadeira, à atenção individualizada, a um ambiente aconchegante, seguro e estimulante, ao contato com a natureza, às boas e adequadas condições de higiene e saúde, a uma alimentação sadia, a desenvolver sua curiosidade, imaginação e capacidade de expressão, ao movimento em espaços amplos, à proteção, afeto e amizade, a expressar seus sentimentos, a uma especial atenção durante seu período de adaptação à creche, a desenvolver sua identidade cultural, racial e religiosa. As autoras defendem que a construção de uma política de creche deve ter como compromisso assegurar os direitos fundamentais da criança, seu bem-estar e desenvolvimento, saúde, alimentação sadia e higiene, a brincadeira, o contato com a natureza e a ampliação de seus conhecimentos.

Rosemberg (2003) sugere também quatro indicadores, embora reconheça as limitações do caso brasileiro: razão função docente/matrícula; formação 
de profissionais; disponibilidade de material pedagógico; e condições do ambiente físico.

Apenas em 2000 foram estabelecidas metas para a qualidade da educação infantil no Plano Nacional de Educação. Em 2004, a Secretaria de Educação Infantil e Fundamental do Ministério da Educação, em um documento preliminar, propõe padrões de infra-estrutura e parâmetros de qualidade para as instituições (Machado, Campos, 2004). Esse documento revela que ainda não existe consenso entre profissionais da Educação Infantil quanto aos critérios de qualidade adequados à realidade brasileira. A discussão sobre este tema tem movimentado a comunidade científica brasileira, e a literatura disponível indica a urgente necessidade de mais pesquisas nessa área, especialmente sobre creches.

Alguns sugerem estabelecer colaborações, vínculos e relações entre os contextos dos quais as crianças fazem parte, como a casa, a escola, a comunidade, e todos os envolvidos na prestação de serviços para o atendimento e cuidado infantis. Nessa perspectiva, esses contextos imediatos desenvolveriam parcerias visando melhorar as condições de convivência coletiva das crianças, que passam grande parte do dia em instituições como os CEls. Uma destas condições diz respeito aos indicadores sociais, às necessidades de cada criança, assim como de suas famílias e comunidades (Brown et al., 2002; Aguiar, Bairrão, Barros, 2002; Gallager, Clifford, 2000; Katz, 1993).

Evidências de pesquisa, valores profissionais e conhecimento empírico apontam características do ambiente, como, por exemplo, sua organização, as rotinas diárias, tipos de interações existentes, como necessárias para uma educação infantil de qualidade (Aguiar, Bairrão, Barros, 2002; Bondioli, Mantovani, 1998; Zabalza, 1998; Gandini, Edwards, 2002; Katz, 1993). Moss (2006) afirma que "qualidade é um exemplo de avaliação como declaração da realidade, envolvendo a avaliação do desempenho - de uma criança, de um educador ou de um serviço - conforme um conjunto de normas predefinidas" (p. I0). Já que as escalas de medição apresentam problemas no que diz respeito à diversidade e complexidade, valores e subjetividade (Bondioli, 2004), pois levam às múltiplas perspectivas sobre o trabalho pedagógico.

É importante enfatizar que instrumentos como a Infant and Toddlers Environment Rating Scale-Revised - Iters-R [Escala de Avaliação de Ambientes Coletivos para Crianças de 0-30 meses], apesar de representarem uma 
perspectiva específica de avaliação e proposta pedagógica, têm instigado a reflexão sobre os parâmetros de qualidade em vários países, promovendo a ampliação do entendimento sobre ambientes estimulantes para crianças pequenas e sobre o debate acerca da qualidade em si. A idéia de avaliação de ambiente para crianças pequenas tem como principal meta contribuir para o desenvolvimento de ambientes que ofereçam oportunidades para a aprendizagem e a construção do conhecimento para as crianças, as famílias e os professores (Rinaldi, 2002), com ênfase na autonomia e construção do conhecimento. Assim, o emprego desse tipo instrumentos pressupõe o monitoramento da construção dos ambientes, ao invés de privilegiar o valor absoluto em cada subescala e em seus itens. A avaliação do serviço, que pode ser feita de várias formas, como por exemplo, utilizando a Iters-R para servir como norteador da discussão e reflexão sobre a melhoria de todos os aspectos envolvidos (Ferrari, 2003), ajuda a monitorar a qualidade que se pretende atingir. Segundo Ferrari, este tipo de instrumento permite ações de avaliação educativa.

A importância da Iters-R está, em primeiro lugar, na sua estrutura classificatória, que indica diferentes imagens da creche, desde a creche de qualidade insuficiente, capaz de cuidar da criança, até a creche excelente, na qual a autonomia e o bem estar de cada um são garantidos por uma série de projetos educativos, voltados não apenas aos pequenininhos, mas também às relações com as famílias e à promoção da profissão de quem trabalha naquela creche. A lters-R, que define exemplos concretos para cada pontuação diferente, estimula os observadores internos (educadores de creche) e externos (coordenadores, pesquisadores de alguma foram colocados a uma "distância" diferente em relação à creche) a um confronto com aquilo que há e convida a discutir sobre aquilo que deveria haver e, também, sobre o que se desejaria que houvesse. (Ferrari, 2004, p.36)

\section{METODOLOGIA}

\section{Instrumento}

O instrumento utilizado foi a escala Iters (Harms, Cryer, Clifford, 2003), que traduzida e testada em um estudo piloto (Bhering, Campos-de-Carvalho, 
2006), atingindo a confiabilidade necessária entre dois observadores para sua utilização no estudo principal (Kappa: 0,56 a 0,86; Spearman: 0,66 a 0,92).

A escala inclui vários componentes da qualidade da proposta pedagógica e da escola de educação infantil para crianças entre zero e 30 meses (Ferrari, 2003; Aguiar, Bairrão, Barros, 2002), sugeridos por vários profissionais e pesquisadores da área. É composta por sete subescalas (Mobiliário e disposição dos materiais; Rotinas e cuidados pessoais; Linguagem oral e compreensão; Atividades; Interação; Estrutura do programa; e Pais e equipe). As sete subescalas são descritas em 39 itens e possibilitam analisar os elementos e a organização do ambiente, assim como aspectos mais subjetivos conforme quadro I.

Para verificar tendências, a utilização da escala Iters-R possibilitou propor e responder as seguintes questões:

a) Os escores médios obtidos na escala são próximos nos diversos CEls?

b) Os escores médios são próximos, segundo a faixa etária (I, II e III) e a subescala ( I a 7) nos diversos CEls?

Para orientar a discussão sobre o ambiente para crianças pequenas e analisar os CEls, é necessário observar que:

A escala apresenta um critério para a avaliação de todos os seus itens:

I ponto - inadequado, indicando que o cuidado não atende as necessidades básicas de desenvolvimento; 3 pontos - mínimo, indicando que o cuidado básico atende as necessidades básicas e algumas outras necessidades do cuidado e desenvolvimento infantil; 5 pontos - bom, apresentando condições básicas para o cuidado e desenvolvimento infantil; e 7 pontos - excelente, apresentando cuidado de alta qualidade, com atendimento freqüente e personalizado, levando em consideração não só as necessidades do grupo, mas também as especificidades de cada criança.

Essa pontuação permitiu calcular escores médios para cada turma, segundo as sete subescalas.

Procedimento semelhante foi utilizado para calcular escores médios gerais por subescala e faixa etária para todos os CEIS. Adicionalmente foram calculados escores médios por CEl e faixa etária na Iters-R.

Em seguida, os escores médios acima descritos foram classificados em três níveis distintos de qualidade: A) escores entre I e 2,9, indicadores de um 
QUADRO ।

SUBESCALAS E ITENS DA ITERS-R

\begin{tabular}{|c|c|}
\hline Subescalas & Itens \\
\hline I. Espaço e mobiliário & $\begin{array}{l}\text { 1. Espaço interno } \\
\text { 2. Móveis para cuidados de rotina e brincadeiras } \\
\text { 3. Provisões para relaxamento e conforto } \\
\text { 4. Organização da sala } \\
\text { 5. Exposição de materiais para crianças }\end{array}$ \\
\hline 2. Rotinas de cuidado pessoal & $\begin{array}{l}\text { 6. Chegada/Saída } \\
\text { 7. Refeições/merendas } \\
\text { 8. Sono } \\
\text { 9. Troca de fraldas/Uso de banheiro } \\
\text { 10. Práticas de saúde } \\
\text { 11. Práticas de segurança }\end{array}$ \\
\hline 3. Linguagem oral e compreensão & $\begin{array}{l}\text { 12. Auxílio às crianças para compreenderem a linguagem } \\
\text { 13. Auxílio às crianças para usarem a linguagem } \\
\text { 14. Uso de livros }\end{array}$ \\
\hline 4. Atividades & $\begin{array}{l}\text { 15. Motora fina } \\
\text { 16. Atividade física } \\
\text { 17. Arte } \\
\text { 18. Música e movimento } \\
\text { 19. Blocos } \\
\text { 20. Dramatizações } \\
\text { 21. Areia/Água } \\
\text { 22. Natureza/Ciências } \\
\text { 23. Uso de TV, vídeo e/ou computador } \\
\text { 24. Promoção da aceitação de diversidade }\end{array}$ \\
\hline 5. Interação & $\begin{array}{l}\text { 29. Supervisão do brincar e do processo de aprendizagem } \\
\text { 30. Interação criança-criança } \\
\text { 31. Interação equipe-criança } \\
\text { 32. Disciplina }\end{array}$ \\
\hline 6. Estrutura do programa & $\begin{array}{l}\text { 33. Programação } \\
\text { 34. Atividade livre } \\
\text { 35. Atividades em grupo } \\
\text { 36. Medidas para crianças com necessidades especiais }\end{array}$ \\
\hline 7. Pais e equipe & $\begin{array}{l}\text { 37. Medidas para o envolvimento dos pais } \\
\text { 38. Medidas para as necessidades pessoais da equipe } \\
\text { 39. Medidas para atender as necessidades profissionais da } \\
\text { equipe } \\
\text { 40. Interação e cooperação entre a equipe } \\
\text { 41. Estabilidade da equipe } \\
\text { 42. Supervisão e avaliação da equipe } \\
\text { 43. Oportunidades para desenvolvimento profissional }\end{array}$ \\
\hline
\end{tabular}


nível baixo de qualidade; B) escores entre 3 e 4,9, indicadores de um nível satisfatório de qualidade; e C) escores entre 5 e 7 , indicadores de um alto nível de qualidade.

A escala permite que o observador entreviste os professores e a equipe para complementar os dados das subescalas, e que identifique aspectos que não são passíveis de observação (como por exemplo, o tipo de formação continuada programada, rodízio de exposição dos trabalhos das crianças etc).

Esse instrumento foi utilizado na região de Emilia-Romagna, na Itália (Ferrari, 2004), e permitiu aos coordenadores e educadores de creche discutir critérios de avaliação da qualidade e o conceito de qualidade que se queria compartilhar. A escala foi traduzida para vários idiomas e tem sido aplicada em pesquisas em vários países, comprovando que há fidedignidade e bons níveis de confiabilidade.

Este estudo contou com a colaboração da Secretaria Municipal de Educação, que autorizou nossa presença nas salas, com a expectativa de se beneficiar tanto do processo de coleta de dados como dos resultados da pesquisa.

\section{Turmas observadas}

A Iters-R foi aplicada em 12 turmas de Centros de Educação Infantil do município, das quais nove, vinculadas à rede municipal e três, à iniciativa privada sem fins lucrativos. A idade das crianças variava de três meses a 38 meses, e a maioria das turmas contava com uma educadora e uma assistente. Os CEls funcionam em período integral, a partir das 4 horas da manhã até as 18 horas, mas um deles permanece aberto até as 23h30min para atender a demanda dos pais que fazem turno noturno numa indústria têxtil (Tab. I). A maioria da população município é de origem germânica e mais da metade das professoras é bilíngüe. É importante mencionar que as vagas reservadas para as indústrias não comprometem a demanda regular do município.

Segundo dados da Secretaria de Educação do Município, toda a demanda para educação infantil de crianças entre zero e três anos é atendida pelos cinco CEls. Um dos centros urbanos registra maior demanda, porém, quando o número total de vagas é preenchido, as crianças são encaminhadas para outros centros (na maioria das vezes rurais). A cidade tinha uma população de | | I | 4 crianças entre zero a três anos, em 2004, segundo o Censo do IBGE, para um 
TABELA I

CARACTERÍSTICAS DOS CEIS

\begin{tabular}{|c|c|c|c|c|c|c|c|c|c|c|c|c|}
\hline & \multicolumn{3}{|c|}{ CEI I (Urbano) } & \multicolumn{2}{|c|}{ CEI 2 (Urbano) } & \multicolumn{2}{|c|}{ CEI 3 (Rural) } & \multicolumn{2}{|c|}{ CEI 4 (Rural) } & \multicolumn{3}{|c|}{ CEI 5 (Urbano) } \\
\hline Crianças matriculadas & \multicolumn{3}{|c|}{176} & \multicolumn{2}{|c|}{70} & \multicolumn{2}{|c|}{39} & \multicolumn{2}{|c|}{16} & \multicolumn{3}{|c|}{135} \\
\hline Crianças de 0 a 3 anos & \multicolumn{3}{|c|}{76} & \multicolumn{2}{|c|}{39} & \multicolumn{2}{|c|}{17} & \multicolumn{2}{|c|}{11} & \multicolumn{3}{|c|}{72} \\
\hline Turmas observadas & \multicolumn{3}{|c|}{ I, II, III } & \multicolumn{2}{|c|}{ I, II } & \multicolumn{2}{|c|}{ I, II } & \multicolumn{2}{|c|}{ I, II } & \multicolumn{3}{|c|}{ I, II, III } \\
\hline $\begin{array}{l}\text { Horário de } \\
\text { funcionamento }\end{array}$ & \multicolumn{3}{|c|}{$\begin{array}{l}4 h 30 \text { às } \\
23 h 30\end{array}$} & \multicolumn{2}{|c|}{$\begin{array}{l}4 \mathrm{~h} 30 \text { às } \\
18 \text { horas }\end{array}$} & \multicolumn{2}{|c|}{$\begin{array}{l}4 \text { horas às } \\
19 \text { horas }\end{array}$} & \multicolumn{2}{|c|}{$\begin{array}{l}4 \text { horas às } \\
18 \text { horas }\end{array}$} & \multicolumn{3}{|c|}{$\begin{array}{l}4 \text { h30 às } \\
18 \text { horas }\end{array}$} \\
\hline $\begin{array}{l}\text { Vagas disponibilizadas } \\
\text { para indústrias do } \\
\text { município gerando } \\
\text { recurso para a } \\
\text { instituição de El }\end{array}$ & \multicolumn{3}{|c|}{$\frac{60}{\text { Têxtil }}$} & \multicolumn{2}{|c|}{$\begin{array}{l}\underline{3} \\
\text { Químico e } \\
\text { peças de } \\
\text { maquinário }\end{array}$} & \multicolumn{2}{|c|}{-} & \multicolumn{2}{|c|}{-} & \multicolumn{3}{|c|}{$\begin{array}{c}\underline{8} \\
\text { Têxtil, } \\
\text { brinquedos, } \\
\text { porcelana, peças } \\
\text { de maquinário }\end{array}$} \\
\hline \multirow{2}{*}{$\begin{array}{l}\text { Crianças presentes } \\
\text { durante coleta de dados }\end{array}$} & T I & T II & T III & T I & T II & $\mathrm{T} \mathrm{I}$ & T II & T I & T II & T I & T II & T III \\
\hline & 8 & 13 & 11 & 7 & 11 & 2 & 3 & 5 & 5 & 12 & 18 & 17 \\
\hline $\begin{array}{l}\text { Professores presentes } \\
\text { durante coleta de dados }\end{array}$ & 2 & 2 & 2 & 2 & 2 & 6 & I & 5 & I & 2 & 2 & 2 \\
\hline $\begin{array}{l}\text { Número de crianças } \\
\text { matriculadas* }\end{array}$ & 25 & 24 & 29 & 14 & 24 & 9 & 8 & 5 & 6 & 14 & 16 & 16 \\
\hline $\begin{array}{l}\text { Número máximo de } \\
\text { crianças permitido por } \\
\text { turma por turno }\end{array}$ & 12 & 16 & 18 & 12 & 16 & 12 & 16 & 12 & 16 & 12 & 16 & 18 \\
\hline Proporção adulto/criança & $1 / 6$ & $1 / 8$ & $1 / 9$ & $1 / 6$ & $1 / 8$ & $1 / 6$ & $1 / 8$ & $1 / 6$ & $1 / 8$ & $1 / 6$ & $1 / 8$ & 1/9 \\
\hline $\begin{array}{l}\text { Adultos designados para } \\
\text { cada turma por turno }\end{array}$ & 2 & 2 & 2 & 2 & 2 & 2 & I & I & 1 & 2 & 2 & 2 \\
\hline
\end{tabular}

* O total de crianças matriculadas por turma l é 25, mas o máximo permitido por turno (manhã, tarde ou integral) é I2. Já no caso das turmas II, o número de crianças matriculadas é 24, mas o máximo permitido por turno é 16.

Obs: Turma I - bebês; Turma II - I a 2 anos; Turma III - 2 a 3 anos.

total de 24.230 habitantes. Nesse mesmo ano, foram registradas 582 matrículas no setor público e 156 no setor privado, totalizando 738 crianças matriculadas nas cinco instituições.

\section{RESULTADOS}

A análise dos dados foi feita de maneira a abordar todos os objetivos específicos. 


\section{Verificar se os cinco CEls têm escores médios gerais próximos}

Os CEls municipais ( I, 2, 3 e 4) obtiveram um escore médio próximo de 4, o que indica um nível de qualidade satisfatório. Pode-se levantar a hipótese de que as ações da Secretaria relacionadas às orientações são consistentes e refletem no trabalho do conjunto de CEls públicos. Já o CEI 5 (privado) obteve um escore médio menor que 3, o que indica nível baixo de qualidade. É importante mencionar que esse CEl apresentou um maior número de crianças por turma comprometendo assim a qualidade do serviço, como por exemplo, a interação adulto/criança na turma I que atende bebês.

Um dado relevante no gráfico 2 são as variações que existem na média das turmas, embora não sejam muito grandes, exceto na turma 3 do CEI I, em que é bem menor, e na turma 2 do CEl 4, em que é bem maior. Esse resultado parece indicar que há em todos os centros consistência entre prática e proposta.

Os resultados das duas únicas turmas para três anos revelam a necessidade de maior atenção ao tratamento das crianças mais velhas. As médias das

\section{GRÁFICO I \\ MÉDIAS DOS CEIS}

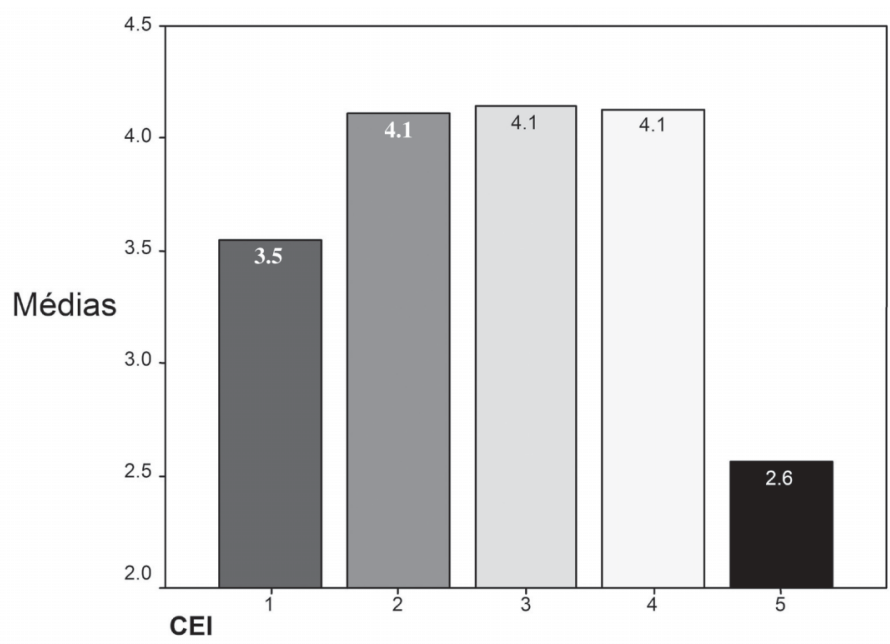


GRÁFICO 2

MÉDIAS POR TURMA EM CADA CEI

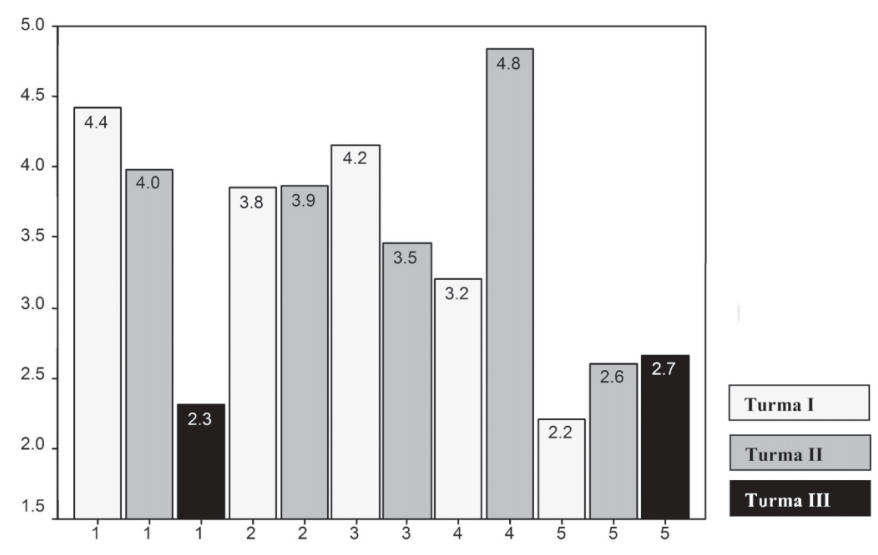

CEl's

turmas 3 (Gráf. 2) dos CEls I e 5 encontram-se no nível baixo de qualidade. Observou-se que nessas turmas havia uma tendência mais escolarizante do que nas turmas das crianças menores, principalmente no que diz respeito às atividades (dirigidas pela professora), à disciplina e ao tipo de rotina. Nesses casos, há uma preocupação maior com conteúdos e produtos finais das atividades, e uma limitação das oportunidades para o desenvolvimento da autonomia e possibilidades de expressão.

Na tabela 2, constata-se que no CEI I as subescalas Rotina de cuidados pessoais, Linguagem oral e compreensão, Atividades, Interação e Estrutura do programa obtiveram escores menores que 2, que correspondem à pontuação entre o inadequado e o mínimo. No CEI 5, as subescalas Rotina de cuidados pessoais, Atividades e Estrutura do programa também receberam escores menores que 2. O que mais chama atenção é o fato de que os escores dessas turmas caíram em relação às outras turmas do mesmo CEl. Há indicações claras de que a proposta sofre mudanças drásticas quando as crianças vão para a turma 3. Rotina de cuidados pessoais e Atividades são as subescalas que merecem maior atenção em todos os centros, mas especialmente nas turmas de crianças entre 2 e 3 anos. $O$ cuidado não atende as necessidades básicas para o desenvolvimento infantil. 
As Rotinas de cuidados pessoais incluem itens que avaliam os momentos de chegada e saída, das refeições e merendas, do sono, da troca de fraldas e do uso do banheiro e das práticas de saúde e segurança. As Atividades referem-se a áreas do currículo que são descritas em subescalas dentro das atividades para o desenvolvimento da motricidade fina, atividade física, arte, música e movimento, blocos, dramatizações, areia/água, natureza/ciências, uso de TV, vídeo e/ou computador, e promoção da aceitação de diversidade. Ambas subescalas revelam a rotina preparada para as crianças e, portanto, influenciam bastante na avaliação e análise da qualidade do serviço para as crianças, e são analisadas em relação ao que está disposto e em relação ao nível de acessibilidade das crianças. Assim, elas enfocam questões pedagógicas tanto nos momentos de cuidados quanto nos das atividades realizadas dentro e fora de sala e, desse modo, permitem ter uma clara visualização da proposta pedagógica para a creche.

Na turma I do CEI 5, a subescala Espaço e mobiliário obteve média 4,4 (Tab. 2), por apresentar vários espaços específicos, por exemplo, uma sala separada para o sono dos bebês e uma cozinha exclusiva, elementos que contribuem para a qualidade do serviço. $O$ respeito pelas crianças nesses momentos de cuidado elevou o escore desse CEI.

\section{Turmas de mesma faixa etária nos CEls: escores por centro e subescala}

O CEI 5 (privado) é mantido por uma entidade religiosa, e a supervisão pedagógica é de responsabilidade de uma das integrantes dessa instituição, cuja prática educativa se baseia em suas crenças religiosas. Observou-se, por exemplo, a preocupação com a disciplina, assim como uma rotina rígida. Essa rigidez pode explicar as baixas pontuações obtidas em algumas subescalas, visto que, em seu conjunto, a escala valoriza práticas que fomentam a autonomia das crianças, mediante uma organização que Ihes permita se auto-orientarem na sala, mas sempre observadas e assistidas pelos adultos. Já no CEI 4, os escores são elevados para as duas turmas avaliadas, o que pode estar relacionado ao conhecimento e à compreensão da proposta pedagógica por parte dos professores, e ao trabalho em torno de objetivos e metas comuns.

Os escores mais elevados em todos os CEls foram obtidos na subescala Interação. Visto que a maioria da população do município é de origem 
TABELA 2

MÉDIAS DAS SUBESCALAS AVALIADAS POR TURMA EM CADA CEI

\begin{tabular}{|c|c|c|c|c|c|c|c|c|c|}
\hline \multirow[b]{2}{*}{ CEI } & \multirow[b]{2}{*}{ Turmas } & \multicolumn{8}{|c|}{ Subescalas } \\
\hline & & \begin{tabular}{|c|} 
Ambiente e \\
mobiliário \\
\\
$(1)$
\end{tabular} & \begin{tabular}{|c|} 
Rotinas de \\
cuidado \\
pessoal \\
$(2)$ \\
\end{tabular} & \begin{tabular}{|c|}
$\begin{array}{c}\text { Linguagem } \\
\text { oral e } \\
\text { compreensão } \\
(3)\end{array}$ \\
\end{tabular} & \begin{tabular}{|c} 
Atividade \\
\\
$(4)$ \\
\end{tabular} & Interação & $\begin{array}{c}\text { Estrutura do } \\
\text { programa } \\
(6)\end{array}$ & $\begin{array}{c}\text { Paise } \\
\text { Equipe } \\
(7) \\
\end{array}$ & Total \\
\hline \multirow[t]{3}{*}{1} & I & 5,2 & 4,8 & 4,7 & 2,6 & 5,7 & 4,3 & 3,6 & 4,4 \\
\hline & II & 4,2 & 3,7 & 2,7 & 3,7 & 5,7 & 3,3 & 4,6 & 3,8 \\
\hline & III & 3,0 & 1,2 & 2,0 & 1,9 & 2,0 & 1,7 & 4,4 & 2,4 \\
\hline \multirow[t]{2}{*}{2} & $\mathrm{I}$ & 4,6 & 3,2 & 5,0 & 2,4 & 5,5 & 2,7 & 3,6 & 4,1 \\
\hline & II & 2,4 & 2,2 & 4,0 & 2,7 & 6,5 & 6,0 & 3,3 & 4,1 \\
\hline \multirow[t]{2}{*}{3} & I & 3,6 & 2,3 & 4,7 & 4,4 & 5,5 & 5,0 & 3,6 & 4,5 \\
\hline & II & 2,6 & 2,0 & 4,3 & 2,11 & 6,2 & 3,3 & 3,6 & 3,8 \\
\hline \multirow[t]{2}{*}{4} & I & 3,0 & 2,3 & 3,0 & 2,4 & 3,2 & 4,7 & 3,7 & 3,3 \\
\hline & II & 5,0 & 4,3 & 5,3 & 4,0 & 6,0 & 4,7 & 6,0 & 5,0 \\
\hline \multirow[t]{3}{*}{5} & I & 4,4 & 1,3 & 1,0 & 1,6 & 1,2 & 1,0 & 4,8 & 2,2 \\
\hline & II & 2,0 & 1,6 & 2,7 & 1,4 & 4,2 & 1,7 & 4,2 & 2,7 \\
\hline & III & 2,2 & 1,8 & 2,7 & 1,6 & 4,2 & 1,7 & 4,4 & 2,8 \\
\hline \multirow[t]{3}{*}{ Total } & I & 4,2 & 2,8 & 3,7 & 2,7 & 4,2 & 3,5 & 3,8 & 3,7 \\
\hline & II & 3,2 & 2,8 & 3,8 & 2,8 & 5,7 & 3,8 & 5,7 & 3,9 \\
\hline & III & 2,6 & 1,5 & 2,3 & 1,7 & 3,1 & 1,7 & 4,4 & 2,6 \\
\hline
\end{tabular}

Médias: entre I e 2,9; entre 3 e 4,9entre 5 e 7 -

Turma I - bebês; Turma II - crianças de I a 2 anos; Turma III - crianças de 2 a 3 anos. Número de turmas observadas $=12$.

germânica, as professoras conversam e interagem com as crianças também em alemão. Essa subescala valoriza justamente o esforço de atender as demandas sociais e culturais das crianças e da comunidade, que podem estar relacionadas a diferenças étnicas ou sociais e a necessidades especiais. Avalia também a disposição dos adultos para as crianças: a supervisão do brincar e do processo de aprendizagem, a interação entre as crianças, a interação entre a equipe e as crianças, e como a disciplina é abordada. Em suma, permite avaliar a importância dada pelos adultos às ações das crianças.

Outra subescala em que os CEls obtiveram escores elevados (nível satisfatório e nível alto de qualidade) foi Pais e equipe, que inclui o envolvimento dos pais; as necessidades pessoais e profissionais da equipe; interação e coo- 
peração da equipe; estabilidade da equipe; supervisão e avaliação da equipe; e oportunidades para desenvolvimento profissional. As entrevistas feitas após a observação revelaram que todos investem na parceria entre pais e equipe, e que os pais são colaboradores importantes para as instituições. Os centros têm horários de funcionamento que permitem o atendimento além do horário comercial, pois o município tem várias indústrias que trabalham 24 horas. A parceria CEl-famílias-indústrias permite contar com recursos extras que complementam o orçamento público e que são revertidos na melhoria do atendimento. Os professores consideram que essa parceria tem sido um fator fundamental para assegurar a qualidade de seus serviços, mas não o único. Ressaltam a importância das oportunidades de formação continuada e das reuniões de equipe como tarefa intrínseca do professor e da equipe pedagógica. A combinação desses dois fatores talvez explique o fato de os CEls públicos terem obtido escores superiores aos dos privados.

A tabela 3 apresenta a média geral das subescalas por CEI e indica que a rede pública deveria dar mais atenção a Rotinas de cuidados pessoais e Atividades, e investir mais nas formações continuadas.

TABELA 3

MÉDIA GERAL DAS SUBESCALAS POR CEIS

\begin{tabular}{|c|c|c|c|c|c|c|c|}
\hline Subescalas & $\begin{array}{c}5 \\
\text { Interação }\end{array}$ & $\begin{array}{c}7 \\
\text { Pais e equipe }\end{array}$ & $\begin{array}{c}\text { । } \\
\text { Espaço e } \\
\text { mobiliário }\end{array}$ & $\begin{array}{c}3 \\
\text { Linguagem oral e } \\
\text { compreensão }\end{array}$ & $\begin{array}{c}6 \\
\text { Estrutura do } \\
\text { programa }\end{array}$ & $\begin{array}{c}2 \\
\text { Rotina de } \\
\text { cuidados pessoais }\end{array}$ & $\begin{array}{c}4 \\
\text { Atividades }\end{array}$ \\
\hline Média & 5,7 & 5,3 & 4,4 & 4,3 & 4,1 & 3,2 & 3,2 \\
\hline
\end{tabular}

\section{Investigar a relação entre as subescalas da Iters- $R$ nos CEls}

Foi utilizado o coeficiente de correlação Spearman (um teste não paramétrico que examina pares de variáveis ordinais e/ou intervalos) para verificar a relação entre as subescalas, indicando assim a direção e intensidade da relação entre elas.

A presença de valores altos para as correlações Spearman com testes estatísticos indica ser significativa a relação entre Estrutura do programa e Atividades; entre Rotina de cuidados pessoais e Atividades; entre Linguagem oral e compreensão $(p<0,01)$. 
Estrutura do programa parece relacionar-se significativamente com Rotinas de cuidado pessoal, Linguagem oral e compreensão e Interação (sendo esta última a subescala que obteve maiores escores nos CEls públicos). Linguagem oral e compreensão também têm relações significativas com Interação e Atividades.

Pais e equipe e Linguagem oral e compreensão e Pais e equipe e Estrutura do programa têm relações significativas, porém, em direções opostas. A

TABELA 4

COEFICIENTE DE CORRELAÇÃO DE SPEARMAN OBTIDO NA AVALIAÇÃO DAS SUBESCALAS NOS CEIS

\begin{tabular}{|c|c|c|c|c|c|c|c|}
\hline Subescalas & $\begin{array}{l}\text { Espaço e } \\
\text { mobiliário }\end{array}$ & $\begin{array}{c}\text { Rotinas de } \\
\text { cuidado } \\
\text { pessoal }\end{array}$ & $\begin{array}{l}\text { Linguagem } \\
\text { oral e } \\
\text { compreensão }\end{array}$ & Atividades & Interação & $\begin{array}{l}\text { Estrutura } \\
\text { do } \\
\text { programa }\end{array}$ & $\begin{array}{l}\text { Pais e } \\
\text { equipe }\end{array}$ \\
\hline & (I) & (2) & (3) & (4) & (5) & (6) & (7) \\
\hline $\begin{array}{l}\text { Espaço e } \\
\text { mobiliário (I) }\end{array}$ & 1.00 & & & & & & \\
\hline $\begin{array}{l}\text { Rotinas de cuidado } \\
\text { pessoal (2) }\end{array}$ & $.66(*)$ & 1.00 & & & & & \\
\hline $\begin{array}{l}\text { Linguagem oral e } \\
\text { compreensão (3) }\end{array}$ & .47 & $.77(* *)$ & 1.00 & & & & \\
\hline Atividades (4) & .53 & $.75(* * *)$ & $.65(*)$ & 1.00 & & & \\
\hline Interação (5) & .096 & $.58(*)$ & $.66(*)$ & $.59(*)$ & 1.00 & & \\
\hline $\begin{array}{l}\text { Estrutura do } \\
\text { programa (6) }\end{array}$ & .15 & $.62(*)$ & $67(*)$ & $.83(* *)$ & $.67(*)$ & 1.00 & \\
\hline Pais e equipe (7) & .016 & -.30 & $-.60(*)$ & -.39 & -.54 & $-.64(*)$ & 1.00 \\
\hline
\end{tabular}

Correlação alta

Correlação muito alta

* Correlação é significativa para o nível de significância de 0.05 (bilateral)

*** Correlação é significativa para o nível de significância de 0.0I (bilateral)

Turmas I - bebês; Turma II - crianças de I a 2 anos; Turma III - crianças de 2 a 3 anos número de turmas observadas $=12$ 
subescala Pais e equipe foi a segunda com escores médios mais altos e, portanto, merece maior investigação. Relações com os pais e entre a equipe são aspectos que devem ser constantemente valorizados e trabalhados para criar um clima positivo e construtivo para as crianças e todos aqueles que lidam direta ou indiretamente com elas. A subescala Estrutura do programa ressalta a natureza das atividades oferecidas às crianças no sentido de balancear os tipos de atividades ao longo do dia. Já a subescala Pais e equipe permite uma reflexão sobre a formação dos profissionais de maneira a atender as suas necessidades, com vistas à melhoria daquilo que é oferecido às crianças e suas famílias. Linguagem oral e compreensão destaca as oportunidades que as crianças têm de se expressar verbalmente, assim como de compreender o que acontece ao seu redor.

Espaço e mobiliário só se correlacionou significativamente com Rotinas de cuidados pessoais. Estes resultados indicam novas possibilidades de pesquisa no que diz respeito à construção de ambientes para creche. Há indícios de importantes correlações entre as subescalas que precisam ser mais amplamente investigadas.

\section{CONSIDERAÇÕES FINAIS}

Os autores da escala sustentam que ela pode ser útil tanto para o monitoramento das ações da instituição como para as pesquisas. Apesar de descrever previamente os indicadores de qualidade e pressupor que as instituições avaliadas trabalham dentro da perspectiva construtivista, esse instrumento abre possibilidades para a reflexão e discussão sobre os indicadores considerados, ampliando a compreensão de todos sobre temas e tópicos relevantes para a educação de crianças entre zero e três anos. $\bigcirc$ instrumento indica a importância da interação com a equipe da instituição para obter dados sobre os aspectos que não são facilmente observáveis no seu dia-a-dia. Além disso, quando a equipe se familiariza com o instrumento, desperta nela o interesse pelos aspectos que nem sempre são pensados e considerados no trabalho com as crianças e com a equipe. A discussão sobre qualidade do ambiente não se esgota na identificação das necessidades do grupo de crianças e adultos e, portanto, outras abordagens podem contribuir para a ampliação do conceito.

Este estudo, além de avaliar as condições do ambiente dos cinco centros de educação infantil, pretendia explorar a Iters-R de maneira a perceber 
seu alcance. Aparentemente, ela consegue captar a dinâmica da instituição e avaliar de forma minuciosa a preparação do ambiente para as crianças, observando seu uso. Partindo do pressuposto de que estamos criando contextos de desenvolvimento infantil, assim como de desenvolvimento (pessoal e profissional) dos adultos envolvidos nesses ambientes educativos coletivos, a escala considera as várias oportunidades que podem ser oferecidas de maneira a priorizar os interesses da criança e sua relação com o mundo. Assim, priorizase também a formação inicial e continuada dos profissionais. Zabalza (1998) ressalta a importância desse aspecto, e afirma que esse é um dos elementos básicos para a educação infantil de qualidade. Além disso, a escala indica a necessidade de verificar as mudanças que ocorrem nestes ambientes ao longo do ano, e para isso se encontram indicações nas Notas de Esclarecimento de como proceder para captar essas mudanças e ampliar a avaliação do ambiente para além do período em que foram feitas as observações.

$\bigcirc$ instrumento possibilitou verificar, nas instituições investigadas, os seguintes pontos:

- A presença de mobiliário adequado ao tamanho adulto, como cadeiras e outros equipamentos. Isso foi observado em poucas turmas, e esse é um dado importante, uma vez que os adultos passam longas horas em serviço e necessitam de uma estrutura que atenda suas necessidades físicas.

- cuidado com a limpeza das salas e a organização dos pertences das crianças, que indica o grau de preocupação com o bem-estar, a saúde e a higiene das crianças e dos adultos envolvidos (Campos, Rosemberg, 1995).

- A disponibilidade de materiais diversos, apesar de não estarem acessíveis o tempo todo, o que compromete a autonomia das crianças e revela a predominância de atividades dirigidas pelas professoras. Há espaços para brincadeira, mas que parecem limitar-se às referencias dadas pelas professoras.

- A grande variedade e número de brinquedos e materiais para uso em situações diversas, e pouca utilização de sucata que, segundo Rosemberg (2003), constitui 84, I \% dos materiais didáticos disponíveis para as crianças. Este é um aspecto desejável, uma vez que crian- 
ças pequenas ainda disputam brinquedos e materiais sem a perspectiva do compartilhar (Post, Hohmann, 2003).

- Participação ativa da família na gestão da creche com trabalhos voluntários e doações (aspectos físicos, financeiros, organizacionais, festividades etc.), por meio de Associações de Pais.

- Parceria entre comunidade, prefeitura e setor privado. As instituições demonstraram grande satisfação com a parceria com o setor privado, que oferece contribuições voluntárias aos CEls, e com o sistema negociado de vagas com as empresas/indústrias, que não comprometem as vagas públicas.

Os CEls do município estudado estão empenhados em desenvolver um trabalho que responda à demanda da comunidade, incluindo as necessidades tanto das famílias quanto dos principais setores econômicos da região, assim como dos profissionais envolvidos nesse serviço. Não há restrições quanto às parcerias mantidas com os vários setores. Nas observações, verificou-se a dedicação dos profissionais em cada item da escala avaliado, mesmo quando as dificuldades enfrentadas pelas instituições eram visíveis. Apesar da análise indicar que há melhorias a fazer em alguns dos itens da escala, a subescala Interação apresentou os melhores escores. Isso indica investimento nas relações, e oportunidade para as crianças expressarem-se revelando suas necessidades e desejos por meio de conversas, gestos, olhares, músicas etc. nos vários momentos do dia (Bondioli, 1998).

No caso do CEl privado, contatou-se uma diferença nos parâmetros, uma vez que a proposta pedagógica e de intervenção se revelava explicitamente na arrumação e organização das salas e dos materiais para as crianças. Raramente havia materiais disponíveis e acessíveis para elas, o que mostra que era o adulto que decidia sobre a rotina e as atividades (verificou-se haver longas esperas, prioridade a atividades coletivas, muito tempo diante da televisão e pouca interação individualizada). Esta é uma tendência das propostas não centradas nas crianças e nas suas relações com seus iguais e com os adultos, mas nas atividades programadas pelos adultos e dirigidas às crianças. Assim, não se fomenta nas crianças a possibilidade de escolha, a tomada de decisão e consciência sobre o que fazem, naturalmente sob a atenção e cuidados do adulto por meio de interações e mediações construtivas. 
Alguns aspectos relacionados aos professores podem ter influenciado a qualidade das interações: na rede pública, 90\% tinham curso superior e 60\% eram pós-graduados em Educação Infantil. A preocupação da rede municipal com o bem-estar dos adultos foi observada em todos os centros. O CEI I, por exemplo, oferecia sessões semanais de massoterapia para as professoras a fim de minimizar o estresse. Uma vez que trabalhar com crianças pequenas envolve, quase sempre, esforços físicos repetitivos, que podem comprometer o corpo e principalmente a coluna.

A discussão sobre a qualidade de ambientes para crianças entre quatro meses e três anos é tema que merece atenção da comunidade científica devido à relatividade desses serviços. O processo de discussão e de construção de ambientes de qualidade é orgânico, e a preocupação com o atendimento às crianças deve ser constante e prioritária. É a partir da discussão consciente sobre cada aspecto envolvido nestes serviços que ampliaremos nossa compreensão sobre o que é realmente preciso fazer para que esses contextos sejam plenos e fomentadores do desenvolvimento humano, da capacidade de aprendizagem, da socialização e do exercício da cidadania.

Este estudo pretende não apenas avaliar as condições do município pesquisado, mas também desencadear reflexões sobre a complexidade do atendimento às famílias e seus filhos revelada na organização desses ambientes. Apesar de focalizado demais para generalizações, o estudo lança um desafio para novas investigações: problemas relacionados à formação profissional para as instituições privadas (que talvez não tenham assumido o compromisso de formação em serviço e continuada); a parceria com o setor privado para ampliar possibilidades, recursos e atendimento; a expansão dos serviços para atender 100\% da demanda municipal; o número excessivo de crianças nas turmas comprometendo a qualidade do serviço; e as reflexões sobre as rotinas de cuidados pessoais e atividades (incluídas na programação diária para crianças que passam grande parte de sua infância em uma instituição). E, finalmente, estimula a reflexão sobre o uso de um instrumento para monitorar a construção permanente do ambiente das nossas instituições sem comprometer a individualidade e a peculiaridade das que já existem e daquelas que ainda se quer construir e, principalmente, que demonstre o processo de desenvolvimento e a dinâmica do ambiente e das ações de todos os envolvidos, impulsionando o processo de mudanças necessárias para a melhora da qualidade do conjunto e o processo de auto-reflexão. 


\section{REFERÊNCIAS BIBLIOGRÁFICAS}

AGUIAR, C.; BAIRRÃO, J.; BARROS, S. Contributos para o estudo da qualidade em contextos de creche na área metropolitana do Porto. Revista do GEDEl: Infância e Educação. Investigação e Practicas, n.5, p.7-28, dez. 2002.

ARIÉS, P. História social da criança e da família. Rio de Janeiro: Guanabara, 1986.

BECCHI, E.; BONDIOLI, A. (orgs.) Avaliando a pré-escola: uma trajetória de formação de professoras. Campinas: Autores Associados, 2003.

BHERING, E. Educação infantil: uma iniciativa produzida pela união de recursos e competências. Contrapontos, v.4. n. I, p. I I-2I, jan./abr.2004.

BHERING, E.; CAMPOS-DE-CARVALHO, M. Escala de avaliação de ambientes coletivos para crianças entre 0 e 30 meses, 2006. mimeo

BOMFIM, J. A. O. Arranjos espaciais e ocupações do espaço por crianças de 1-2 e 3-4 anos em creche. Ribeirão Preto, 2002. Dissert. (mestr.) Universidade de São Paulo.

BONDIOLI, A.; MANTOVANI, S. Manual de educação infantit: de 0 a 3 anos - uma abordagem reflexiva. Porto Alegre: Artmed, 1998. p.212-221.

(org.) O Projeto pedagógico da creche e a sua avaliação: a qualidade negociada. Campinas: Autores Associados, 2004.

BROWN, E. G. et al. The Continuity framework: a tool for building home, school, and community partnerships. Early Childhood Research \& Practice, v.4, n.2, Fall 2002. Disponível em: http://ecrp.uiuc.edu/v4n2/brown.html. Acesso em: 13 out.2004.

CAMPOS, M. M.; ROSEMBERG, F. Critérios para um atendimento em creches que respeite os direitos fundamentais das crianças. Brasília: Ministério da Educação, Secretaria de Educação Fundamental, Departamento de Políticas Educacionais, Coordenação Geral de Educação Infantil, 1995.

CAMPOS-DE-CARVALHO, M. I.; PADOVANI, F. H. P. Agrupamentos preferenciais e nãopreferenciais e arranjos espaciais em creches. Estudos de Psicologia, Natal, v. 2, n.5, p. $443-$ 470, 2000.

CAMPOS-DE-CARVALHO, M.; RUBIANO, M. R. B. Organização do espaço em instituições pré-escolares. In: OLIVEIRA, Z. M. R. de (org.) Educação infantik muitos olhares. São Paulo: Cortez, 1996. p. I07-130.

Rede social de crianças pequenas em creches: análise por proximidade física e atividade compartilhada. Psicologia: Teoria e Pesquisa, Brasília, v.2, n. I2, p. I29- I36, 1996 a. 
DEMO, P. A Política de educação infantil no contexto da política da infância no Brasil. In: SIMPÓSIO DE EDUCAÇÃO INFANTIL. Brasília, 1994. Anais. Brasília: MEC, 1994. p.22.

FERRARI, M. Um percurso de formação em Pistóia. In BECCHI, E.; BONDIOLI, A. (orgs.) Avaliando a pré-escola: uma trajetória de formação de professoras. Campinas: Autores Associados, 2003. p.7-36.

Qualidade negociada. In: BONDIOLI, A. (org.) O Projeto pedagógico e a sua avaliação. Campinas: Autores Associados, 2004. p. 1 3-33.

GALLAGER, J.; CLIFFORD, R. The Missing support infrastructure in early childhood. Early Childhood Research \& Practice, v. 2, n. I, Spring 2000. Disponível em: http://ecrp.uiuc.edu/ 2vnl/gallagher.html. Acesso em: 13 out.2004.

GANDINI, L.; EDWARDS, C. (orgs.) Bambini: a abordagem italiana à educação infantil. Porto Alegre: Artmed, 2002.

GUIMARÃES, J. L. O Financiamento da educação infantil: quem paga a conta? In: MACHADO, M. L. de A. (org.) Encontros e desencontros na educação infantil. São Paulo: Vozes, 2002. p.43-57.

HADDAD, L. Substituir ou compartilhar? O papel das instituições de educação infantil no contexto da sociedade contemporânea. In: MACHADO, M. L. de A. (org.) Encontros e desencontros em educação infantil. São Paulo: Vozes, 2002. p.91-86.

HARMS, T.; CRYER, D.; CLIFFORD, R. Infant and toddler environment rating scale revised. Estados Unidos: Teachers College Press, 2003.

KATZ, L. G. Five perspectives on quality in early childhood programs. S.I.: ERC, 1993.

LORDELO, E. da R. Contexto e desenvolvimento humano: quadro conceitual. In: LORDELO, E. R.; CARVALHO, A. M. A.; KOLLER, S. H. (orgs.) Infância brasileira e contextos de desenvolvimento. São Paulo: Casa do Psicólogo; Salvador: Edufba, 2002. p.5-18.

MACHADO, M. L. A.; CAMPOS, M. M. Parâmetros de qualidade para a educação infantil. Brasília: Ministério da Educação, Secretaria de Educação Infantil e Fundamental, 2004. (Documento preliminar)

BRASIL. Ministério da Educação. Plano Nacional de Educação.Brasília: Secretaria de Educação Infantil e Fundamental, 2000.

MOSS, P. As Diversas linguagens da avaliação. Revista Pátio Educação Infantil. Porto Alegre: Artmed, n. 10, p 9-1।, 2006.

Para além do problema com qualidade. In: MACHADO, M. L. de A. (org.)

Encontros e desencontros em educação infantil. São Paulo: Vozes, 2002. p. I7-26. 
NABUCO, M. E. Estudos sobre os efeitos de três currículos de educação pré-escolar em Portugal no fim do primeiro ano da educação básica. Contrapontos, v.4, n. I . jan./abr. 2004. POST, J.; HOHMANN, M. Educação de bebés em infantários. cuidados e primeiras aprendizagens. Lisboa: Fundação Calouste Gulbenkian, 2003.

RINALDI, C. Reggio Emilia: a imagem da criança e o ambiente em que ela vive como princípio fundamental. In: GANDINI, L.; EDWARDS, C. (orgs.) Bambini. a abordagem italiana à educação infantil. Porto Alegre: Artmed, 2002. p.75-80.

ROSEMBERG, F. Panorama da educação infantil brasileira contemporânea. In: SIMPÓSIO EDUCAÇÃO INFANTIL, Brasília, 2002. Anais. Brasília: Unesco, 2003. p.33-6I.

SAGER, F. et al. Avaliação da interação de crianças em pátios de escolas infantis: uma abordagem da psicologia ambiental. Psicologia: Reflexão e Crítica, v. I , n. I 6, p.203-2 I 5, 2003.

SALUJA, G.; EARLY, D. M.; CLIFFORD, R. M. Demographic characteristics of early childhood teachers and structural elements of early care and education in the United States. Early Childhood Research \& Practice, v. 4, n. I, Spring 2002. Disponível em: http://ecrp.uiuc.edu/ v4nl/saluja.html.

ZABALZA, M. A. Qualidade em Educação Infantil. Porto Alegre: Artmed, 1998.

Recebido em: maio 2006

Aprovado para publicação em: maio 2006 